\title{
Long-term Neuropsychiatric and Neuropsychological Sequelae of Endovascularly Treated Aneurysmal Subarachnoid Hemorrhage
}

\author{
Sequelas Neuropsiquiátricas e Neuropsicológicas, \\ a Longo Prazo, de Hemorragia Subaracnoideia \\ Aneurismática Tratada Endovascularmente
}

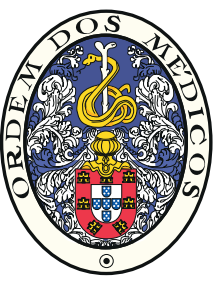

Lídia SOUSA $\triangle^{1}$, Ana ANTUNES¹, Tiago MENDES¹, Sofia REIMÃO², Lia Lucas NETO², Jorge CAMPOS²

Acta Med Port 2019 Nov;32(11):706-713 - https://doi.org/10.20344/amp.10894

\section{ABSTRACT}

Introduction: There is limited evidence regarding long-term outcomes of aneurysmal subarachnoid hemorrhage survivors. Most follow-up programs are relatively short and focused on physical functions. Endovascular aneurysmal embolization enables recovery of normal vascular architecture. However, there is growing evidence that neuropsychological and behavior sequelae can significantly impact the lives of these patients, even when treatment is successful. In this study, we reviewed cognition, psychiatric and neuropsychological symptoms, global functionality, and health-related quality of life 10 to 12 years after an aneurysmal subarachnoid hemorrhage. Material and Methods: A cross-sectional observational study was carried out in a university hospital. All cases of aneurysmal subarachnoid hemorrhage admitted between January 2004 and December 2006 and endovascularly treated were reviewed. Participants underwent a neuropsychological evaluation and a clinical interview with a psychiatrist.

Results: Fourteen patients participated in the study. Almost $70 \%(n=10)$ showed cognitive impairment; in more than $40 \%(n=6)$ of the subjects, significant symptoms of anxiety were identified, and $35 \%(n=5)$ were classified as having clinical depression. Relevant posttraumatic symptoms were reported by more than $70 \%(n=10)$ of patients, and almost $30 \%(n=4)$ showed other moderate neuropsychiatric symptoms. Overall, health-related quality of life was impaired, and personality changes were frequently reported by the participants and their relatives.

Discussion: A significant prevalence of ongoing deficits in high-level functioning and reduced health-related quality of life were observed in a sample of young and professionally active individuals that were successfully treated and discharged from follow-up consultations. Conclusion: There is a need for better follow-up strategies, targeting more subtle deficits and psychological symptoms after aneurysmal subarachnoid hemorrhage.

Keywords: Activities of Daily Living; Endovascular Procedures; Mood Disorders; Subarachnoid Cognitive Dysfunction; Subarachnoid Hemorrhage/complications

\section{RESUMO}

Introdução: As evidências sobre a evolução a longo prazo dos sobreviventes de uma hemorragia subaracnoideia aneurismática são relativamente limitadas. A maioria dos programas de follow-up têm uma curta duração e são focados principalmente nas funções motoras. Apesar da embolização aneurismática endovascular permitir uma recuperação da arquitetura vascular normal, há evidências crescentes de que certas sequelas neuropsicológicas e comportamentais podem afetar significativamente a vida desses pacientes, a longo prazo, mesmo quando o tratamento é bem-sucedido. Neste estudo, analisamos os sintomas cognitivos, psiquiátricos e neuropsicológicos, a funcionalidade global e a qualidade de vida relacionada com a saúde, 10 a 12 anos após uma hemorragia subaracnoideia aneurismática.

Material e Métodos: Um estudo observacional, transversal, foi realizado num hospital universitário. Todos os casos de hemorragia subaracnoideia aneurismática, admitidos entre janeiro de 2004 e dezembro de 2006, tratados endovascularmente, foram revistos. Os participantes foram sujeitos a uma avaliação neuropsicológicas e a uma entrevista clínica com um psiquiatra.

Resultados: Participaram no estudo 14 doentes. Cerca de 70\% $(n=10)$ apresentavam compromisso cognitivo; em mais de $40 \%$ $(n=6)$ foram identificados sintomas significativos de ansiedade e $35 \%(n=5)$ foram classificados como tendo depressão clínica. Sintomas de stress pós-traumático relevantes foram relatados por mais de $70 \%(n=10)$ e quase $30 \%(n=4)$ apresentavam sintomas neuropsiquiátricos moderados. Em geral, a qualidade de vida relacionada com o estado de saúde encontrava-se reduzida e relatos de alterações de personalidade foram frequentemente feitos pelos participantes e seus familiares.

Discussão: Uma prevalência significativa de défices em altos níveis de funcionamento e uma redução da qualidade de vida relacionada com a saúde foi observada numa amostra de indivíduos jovens e profissionalmente ativos, que foram tratados com sucesso e tiveram alta das consultas de seguimento.

Conclusão: São necessárias melhores estratégias de follow-up, visando défices cognitivos e sintomas psicológicos mais subtis, após uma hemorragia subaracnoideia aneurismática.

Palavras-chave: Atividades da Vida Diária; Hemorragia Subaracnoideia/complicações; Perturbações da Cognição; Perturbações do Humor; Procedimentos Endovasculares

\footnotetext{
1. Department of Psychiatry and Mental Health. Santa Maria University Hospital. Lisbon. Portugal.

2. Department of Neuroradiology. Santa Maria University Hospital. Lisbon. Portugal.

$\bowtie$ Autor correspondente: Lídia Sousa. lidiasousa99@gmail.com

Recebido: 02 de junho de 2018 - Aceite: 03 de junho de 2019 | Copyright @ Ordem dos Médicos 2019
} 


\section{INTRODUCTION}

The rupture of an intracranial aneurysm, causing subsequent accumulation of blood in the subarachnoid space, is a life-changing event associated with substantial morbidity, aside from a mortality rate of approximately $50 \%$ in the acute phase. ${ }^{1}$ Despite the relatively low incidence, affecting around 9 subjects per 100000 person-years worldwide, ${ }^{2}$ the relatively young age of occurrence makes it even more striking in terms of public health. Peak incidence is estimated between $40-60$ years of age, ${ }^{3}$ thus affecting people that are still in the most productive years of their life and are expected to carry on with many personal and professional responsibilities. Many studies report up to $40 \%$ of survivors not being able to return to work, ${ }^{4-7}$ and some only being able to take on fewer responsibilities and/or work for fewer hours. ${ }^{4,8-10}$

Most studies evaluating the cognitive status of survivors focused on short-term outcomes. In a Portuguese sample of 108 acute subarachnoid hemorrhage (SAH) patients (61 aneurysmal, 47 non-aneurysmal), Caeiro et al found a high percentage of neuropsychiatric disturbances: depression $(45 \%)$, apathy $(42 \%)$, denial $(21 \%)$, and catastrophic reaction $(17 \%){ }^{11}$

While it is almost consensual that memory, executive function, and language deficits are common cognitive sequelae of an aneurysmal subarachnoid hemorrhage (aSAH), there is still a lot to be known regarding long-term outcomes many years after the event. Recent studies have created controversy: for example, by reporting cognitive recovery during the first years and a new decline in subsequent years. ${ }^{12}$

Changes in personality and significant mental health symptoms have also been reported following SAH. In one of the longest post-SAH evaluation studies (a mean follow-up after aSAH of 8.9 years), the authors described that almost $60 \%$ of the patients reported changes in personality, with increased irritability being present in $37 \%$ and increased 'emotionality' in almost $30 \%$ of the sample. ${ }^{7}$ It is consensual that, at least in the short term, the quality of life after SAH is significantly impaired; however, much remains to be investigated, ${ }^{13}$ particularly concerning long-term outcomes.

The aim of the present study is to assess and describe the cognitive status, specific psychiatric (anxiety, depression, and posttraumatic stress) and neuropsychiatric symptoms, functional impairment, and health related quality of life (HRQL) in a cohort of 10- to 12- year survivors of aSAH that underwent endovascular treatment.

\section{MATERIAL AND METHODS}

This cross-sectional observational study was carried out in a university hospital where approval was obtained from the Ethics Committee. The study followed the Declaration of Helsinki, and informed written consent was obtained before any procedure. Hospital records were assessed to obtain clinical information about the admission, treatment, and follow-up of the patients. Participants were invited to a single session that combined an interview with a psychiatrist and a neuropsychological evaluation.
The neuropsychological assessment, performed by an experienced neuropsychologist, included the Subjective Memory Complaints Scale ${ }^{14}$ and the Montreal Cognitive Assessment (MoCA $)^{15}$ and lasted about 20 minutes. After a short break of at least 30 minutes, the Instrumental Activities of Daily Living Questionnaire, ${ }^{16}$ the Quality of Life Questionnaire (short form 36), ${ }^{17,18}$ the Hospital Anxiety and Depression Scale, ${ }^{19}$ the Neuropsychiatric Inventory, ${ }^{20}$ and the Posttraumatic Stress Diagnostic Scale ${ }^{21}$ were performed by two trained psychiatrists. The second part of the evaluation had an approximate duration of 40 minutes.

All cases of aSAH admitted between January 2004 and December 2006 and endovascularly treated were reviewed.

Patients were considered suitable for full assessment and participation if the following inclusion criteria (IC) were met: (a) spontaneous subarachnoid hemorrhage (aSHA) with angiography-confirmed etiology of intracranial aneurysmal rupture and receipt of endovascular treatment, (b) neurological recovery without signs of focal neurological deficits, and (c) informed consent from the patient or a legal representative before any procedure. Exclusion criteria were the following: a previous diagnosis of dementia; intellectual disability; age under 18 or above 60 years at the time of aSAH; unwillingness or incapacity to cooperate; a previous diagnosis of a major psychiatric disorder; a previous history of cerebral trauma, stroke, neurosurgical intervention, or another major neurological event before the aSAH.

Forty-three patients were identified through hospital records, and it was possible to get in contact with 29 of them. A total of 15 patients complied with the inclusion criteria and agreed to participate. One patient dropped out before the beginning of the study due to an unexpected personal issue, and another dropped out during the study, having completed only half of the clinical evaluation. The recruitment and sample composition $(n=14)$ are illustrated in Fig. 1.

The checklist of items of the STrengthening the Reporting of OBservational studies in Epidemiology Statement, ${ }^{22}$ which should be included in reports of observational studies, was used.

\section{Clinical measurement outcomes}

Montreal Cognitive Assessment (MoCA) is a 30-point test validated in the setting of mild cognitive impairment ${ }^{23}$ and frequently used as a cognitive screening assessment tool in the context of vascular events such as aSAH. ${ }^{24}$ It includes six subtests (visuospatial/executive function, naming, attention, abstraction, recall, and orientation), with more emphasis on tasks involving frontal executive function and attention. ${ }^{23}$ There is compelling evidence that MoCAassessed cognitive function is an important determinant of good outcomes after aSAH. ${ }^{25}$

The Subjective Memory Complaints Scale (SMCS) ${ }^{26}$ is a brief, self-rated questionnaire for the detection of common memory complaints. It consists of 10 items concerning difficulties in daily-life memory tasks, with the total score ranging from 0 (absence of complaints) to 21 (maximum 
Hospital Records Assessed $(n=43)$

Deceased Patients $(n=7)$

4 cases $<1$ month after aSAH

3 cases $>1$ years after aSAH

Patients with no contact available $(n=7)$

Patients contacted $(n=29)$

Declines to participate $(\mathbf{n}=\mathbf{6})$
3 Not interested
3 Lived far away

\begin{tabular}{|c|}
\hline Not meeting IC $(\mathbf{n}=\mathbf{8})$ \\
6 Aged $>60$ \\
1 severe neurological deficits \\
1 severe cognitive deficits \\
\hline
\end{tabular}
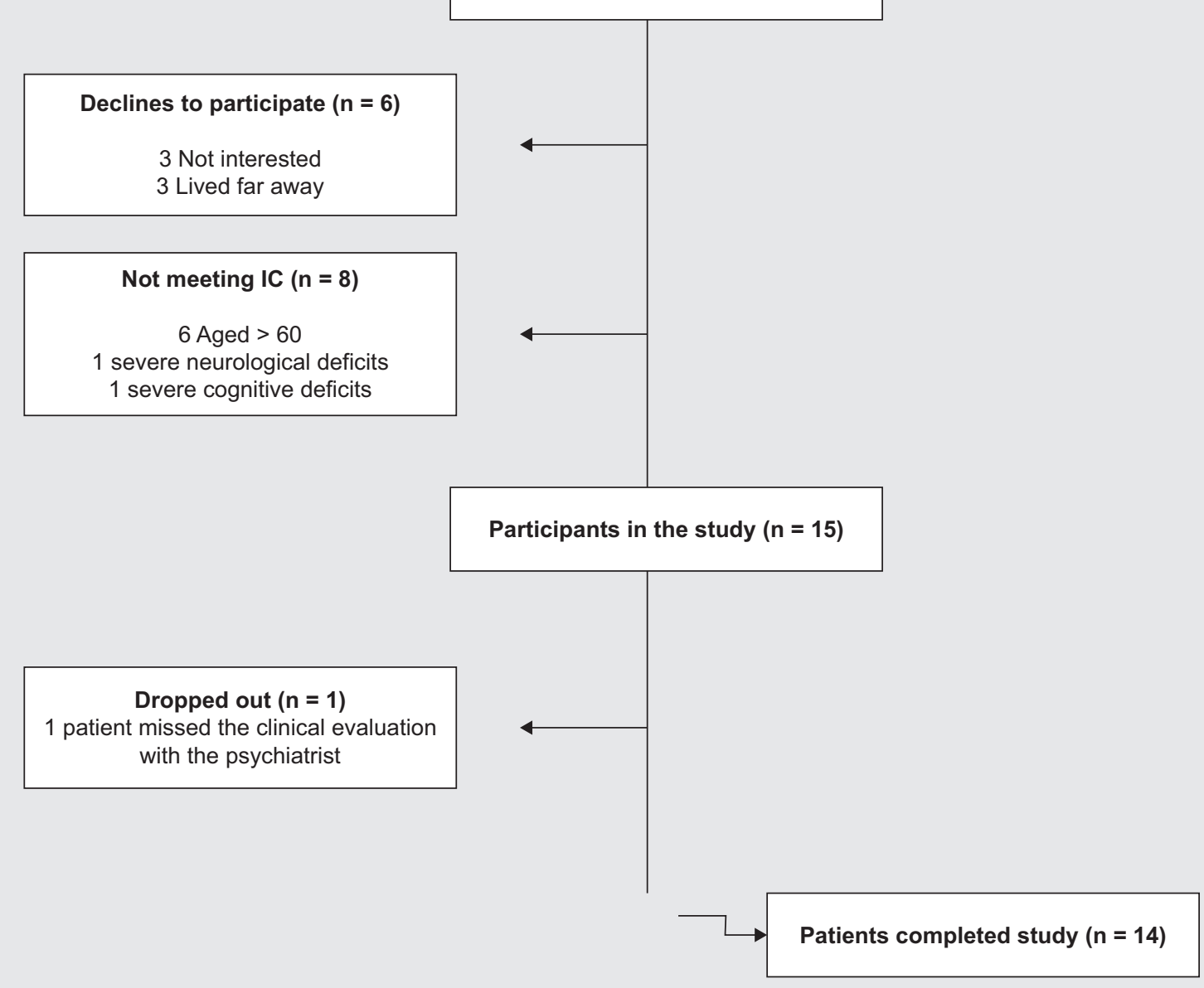

Figure 1 - Sample composition and recruitment

complaints score). A score equal to or lower than 3 implies that the complaints have no relevance. The Portuguese version of the scale, adapted from Ginó et al, ${ }^{14}$ was used.

Instrumental Activities of Daily Living (IADL) is an instrument to assess independent living skills through eight domains of cognitive or physical function (telephoning, shopping, food preparation, housekeeping, laundering, use of transportation, use of medication, and financial behavior), with a practical utility in widely diverse settings, for population groups of different ages, and for a variety of goals. ${ }^{27}$

The Quality of Life Questionnaire (QoL) (short form 36, SF36) is a 36-item, patient-reported survey that consists of eight scaled scores (vitality, physical functioning, bodily pain, general health perceptions, physical role functioning, emotional functioning, social functioning, and mental health) along with a summary of physical and mental measures. It is a generic measure of health status as opposed to one 
that targets a specific age group or disease. ${ }^{28}$ Each item is directly transformed into a 0-100 scale, with lower scores representing a higher degree of disability.

The Hospital Anxiety and Depression Scale (HADS) is a self-rated, 14-item scale that includes 7 items related to anxiety and 7 related to depression. This is a questionnaire that performs well in screening for the separate dimensions of anxiety and depression not only in patients from non-psychiatric hospital clinics but also from the general population. ${ }^{29}$ A cut-off of 8 for the subscales of anxiety and depression of HADS was used, as suggested in the literature. ${ }^{29}$

The Neuropsychiatric Inventory Questionnaire (NPI) uses responses from caregivers in a structured interview format to assess 10 behavioral domains (delusions, hallucinations, agitation, dysphoria, anxiety, apathy, irritability, euphoria, disinhibition, and aberrant motor behavior); two additional domains (night-time behavioral disturbance, appetite/ weight changes) are commonly added, resulting in a total of 12 domains. The questionnaire provides symptom severity and distress ratings for each domain of behavioral functioning. ${ }^{30}$ This instrument also allows caregiver disruption assessment; for each of the twelve neuropsychiatric symptoms, caregivers rate the level of distress they experience on a scale from 0 (none) to 5 (very severe)..$^{30}$ Here, we considered a caregiver to be the closest relative that the patient identified and brought to the evaluation.

The Posttraumatic Stress Diagnostic Scale (PTSDS) focuses on evaluating the experience of a potentially traumatic event in order to provide both a measure of PTSD symptom severity and a PTSD diagnosis. It includes 17 self-reported items regarding symptoms experienced in the previous month. ${ }^{31}$ In this study, we used the civilian version ${ }^{21}$ of this scale, and the sum of total scores was considered to screen for significant posttraumatic symptoms. A cut-off of 24 points was considered clinically relevant.

A validated Portuguese version of each of the aforementioned instruments was used.

For qualitative data collection, short semi-structured interviews were conducted with the patient and the family informant before the application of any formal psychological tests. The clinician let the patient and family member talk freely at the beginning of the interview and then asked specific questions about any symptoms arising after subarachnoid hemorrhage, limitations in daily life, and their impact both at a personal and at a social level. Field notes were recorded and analyzed.

\section{Data analysis}

Notes taken during the clinical interviews with a psychiatrist were analyzed at a semantic level and according to a deductive approach. Quotes were used to illustrate recurrent themes. Descriptive statistics were performed in order to characterize sociodemographic and clinical variables. Results were described and interpreted in comparison with normative data for age, gender, and education of the Portuguese population.

\section{RESULTS}

\section{Sample composition}

Seven males and 7 females participated in the study; the mean age at the time of evaluation was 55 years. Four of the patients had the aSAH 10 years prior to the study; in 6 cases the aneurysmal rupture occurred 11 years prior; and the remaining 4 participants had the event 12 years before. In most cases $(78.6 \% ; n=11)$, the brain injury was classified as minor or moderate according to the Glasgow Coma Scale (GCS) at admission. The most common location of a ruptured aneurysm was the anterior circulation (42.9\%; $\mathrm{n}=6)$. Most of the aneurysms were medium $(50 \% ; n=7)$ or small $(35.7 \% ; n=5)$ in dimension. The severity of the hemorrhage according to the Hunt and Hess grading system was grade I in $28.6 \%(n=4)$, grade III in $57.1 \%(n=8)$ and grade $V$ in $14.3 \%(n=2)$ of the cases. All patients were

Table 1 - Sample composition (sociodemographic and clinical data; $\mathrm{n}=14$ )

\begin{tabular}{|c|c|c|}
\hline & $\mathbf{n}$ & $\%$ \\
\hline $\begin{array}{l}\text { Sex } \\
\text { Male } \\
\text { Female }\end{array}$ & $\begin{array}{l}7 \\
7\end{array}$ & $\begin{array}{l}50 \% \\
50 \%\end{array}$ \\
\hline Age (years) & & $\begin{array}{l}93 \\
9\end{array}$ \\
\hline $\begin{array}{l}\text { Education } \\
4 \text { years } \\
5-9 \text { years } \\
10-12 \text { years } \\
\text { Above } 12 \text { years }\end{array}$ & $\begin{array}{l}3 \\
3 \\
4 \\
4\end{array}$ & $\begin{array}{l}21.4 \% \\
21.4 \% \\
28.6 \% \\
28.6 \%\end{array}$ \\
\hline $\begin{array}{l}\text { Marital status } \\
\text { Married } \\
\text { Widowed }\end{array}$ & $\begin{array}{c}12 \\
2\end{array}$ & $\begin{array}{l}85.7 \% \\
14.3 \%\end{array}$ \\
\hline $\begin{array}{l}\text { Brain injury categories } \\
\text { (Time of hospital admission) } \\
\text { Minor: GCS } \geq 13 \\
\text { Moderate: GCS } 9-12 \\
\text { Severe: GCS }<8-9\end{array}$ & $\begin{array}{l}9 \\
2 \\
3\end{array}$ & $\begin{array}{l}64.3 \% \\
14.3 \% \\
21.4 \%\end{array}$ \\
\hline $\begin{array}{l}\text { Hunt and Hess score } \\
1 \\
2 \\
3 \\
4 \\
5\end{array}$ & $\begin{array}{l}4 \\
0 \\
8 \\
2 \\
0\end{array}$ & $\begin{array}{l}28.6 \% \\
0 \% \\
57.1 \% \\
0 \% \\
14.3 \%\end{array}$ \\
\hline $\begin{array}{l}\text { Aneurism location } \\
\text { Anterior circulation } \\
\text { Posterior circulation } \\
\text { Vertebro-basilar } \\
\text { Other }\end{array}$ & $\begin{array}{l}6 \\
4 \\
2 \\
2\end{array}$ & $\begin{array}{l}42.9 \% \\
28.6 \% \\
14.3 \% \\
14.3 \%\end{array}$ \\
\hline $\begin{array}{l}\text { Aneurism size } \\
\text { Small }[2-5[\mathrm{~mm} \\
\text { Medium }[5-10[ \\
\text { Large } \geq 10 \mathrm{~mm}\end{array}$ & $\begin{array}{l}5 \\
7 \\
2\end{array}$ & $\begin{array}{c}35.7 \% \\
50 \% \\
14.3 \%\end{array}$ \\
\hline $\begin{array}{l}\text { Acute complications } \\
\text { Hydrocephalus } \\
\text { Vasospasm }\end{array}$ & $\begin{array}{l}5 \\
3\end{array}$ & $\begin{array}{l}35.7 \% \\
21.4 \%\end{array}$ \\
\hline $\begin{array}{l}\text { Neurological recovery } \\
\text { mRankin } 0-2 \\
\text { mRankin } 3-4 \\
\text { mRankin } 5-6\end{array}$ & $\begin{array}{c}10 \\
4 \\
0\end{array}$ & $\begin{array}{c}71.4 \% \\
28.6 \% \\
0 \%\end{array}$ \\
\hline
\end{tabular}


endovascularly treated with coil placement. Fifty percent of the patients had acute complications, with hydrocephalus being reported in $35.8 \%(n=5)$ of the cases and vasospasm in $51.4 \%(n=3)$ of the cases. A good neurological recovery, defined as a score of 2 or lower in the modified Rankin Scale (mRS) upon discharge, was observed in $71.4 \%$ of the cases $(n=10)$. Patients were in the hospital for 20 days on average, and in only $35.7 \%(n=5)$ of the cases a physical rehabilitation program was performed after discharge. More results on sample composition are presented in Table 1. Table 2 summarizes the main quantitative results of the study.

\section{Qualitative data}

Most patients and/or representative family member reported subjective changes in personality. We selected some quotes that in our opinion illustrate the recurrent theme of personality change, expressed during the interviews: "I easily get irritable and nervous and shout at people... I was not like that before"; "He is not the same person"; "He is more socially disinhibited and irritable"; "He gets really anxious about his performance in simple things"; "My concentration and cognitive performance overall were never the same again... my confidence is also impaired."

Overall, patients were happy to be followed up, with some stating, "It is good to know that the hospital is still keeping an eye on us"; "I have been thinking about going to the doctor to do a check-up, it has been a long time since I had my brain checked"; "There are so many questions that remained in our head... it is good to talk about it"; "It is reassuring to be followed up." Fear of recurrence was expressed by almost all the patients: "We never know when it can happen again." Other recurrent complaints were the difficulty in maintaining concentration and the frequent occurrence of headaches. Some patients also reported that since the event, their self-confidence had decreased significantly, mainly related to cognitive tasks: "I don't feel the same confidence in me... It's difficult for me to concentrate and I get tired easily... I have headaches afterwards when I try harder."

\section{Quantitative data}

Health-related quality of life (HRQL): The SF-36 health-related quality of life score was decreased in all domains when compared with normative data of the Portuguese population. ${ }^{32}$ Vitality and general health perception were the domains with the lowest scores, followed by mental health. Results are detailed in Table 2.

Cognitive deficits and subjective complaints: About $67 \%(n=10)$ of the subjects showed significant cognitive impairment when MOCA scores were compared with normative data of the Portuguese population, taking into account age and education. ${ }^{15}$ Cognitive domains with bad performance were verbal memory and learning $(85.7 \%$ lost at least 2 points out of 5 in the delayed recall test) and visuospatial functions (57.1\% showed some degree of impairment). Subjects lost on average 3 out of 5 points in both domains.

The average score on the SMCS was $4.14(\mathrm{~min}=0$, $\max =10, S D=3.6$ ); when compared with normative data of the Portuguese population, ${ }^{33} 57 \%$ of the patients $(n=8)$ had significant memory complaints. The most frequently reported cognitive complaints were the following: general complaints about memory ( $57 \% ; n=8)$, concentration deficits $(43 \% ; n=6)$, forgetting about where things are left $(43 \%$; $n=6)$, difficulty in finding words $(43 \% ; n=6)$ and being considered forgetful by other people $(43 \% ; n=6)$.

Anxiety and depression: A total of $43 \%(n=6)$ of the subjects scored above the cut-off level of 8 points in the

Table 2 - Summary of main quantitative results

\begin{tabular}{|c|c|c|c|c|}
\hline & Mean & Minimum & Maximum & $\begin{array}{l}\text { Standard } \\
\text { deviation }\end{array}$ \\
\hline \multicolumn{5}{|c|}{ Health related quality of life SF-36 domain scores } \\
\hline Physical functioning & 80 & 45 & 100 & 17.5 \\
\hline General health perception & 62.9 & 30 & 70 & 19.2 \\
\hline Physical role functioning & 76.3 & 18.7 & 81.2 & 29.1 \\
\hline Physical health summary & 67.12 & 32 & 94 & 16.9 \\
\hline Emotional role functioning & 79.2 & 0 & 100 & 30.6 \\
\hline Social role functioning & 76.8 & 25 & 100 & 26.8 \\
\hline Mental health & 67.8 & 20 & 100 & 25 \\
\hline Vitality & 53.9 & 18 & 100 & 25.12 \\
\hline \multicolumn{5}{|l|}{ Cognitive Deficits } \\
\hline MOCA Scores & 21.86 & 14 & 27 & 4.96 \\
\hline \multicolumn{5}{|c|}{ Subjective Memory Complaints } \\
\hline SMCS scores & 4.14 & 0 & 10 & 3.6 \\
\hline \multicolumn{5}{|l|}{ Anxiety and Depression } \\
\hline HADS scores & 10.36 & 0 & 25 & 7.22 \\
\hline \multicolumn{5}{|c|}{ Post-Traumatic-Stress Symptoms } \\
\hline PTSD-c scores & 25.21 & 12 & 49 & 10.06 \\
\hline \multicolumn{5}{|l|}{ Neuropsychiatric Symptoms } \\
\hline NPI scores & 2.08 & 0 & 36 & 12.12 \\
\hline \multicolumn{5}{|l|}{ Activities of Daily Living } \\
\hline IADL scores & 6.93 & 2 & 8 & 1.59 \\
\hline
\end{tabular}


anxiety subscale, and $35.7 \%(n=5)$ were classified as having significant symptoms of depression.

The current use of any psychotropic medication was assessed, and $28.6 \%(n=4)$ of the patients reported regularly taking at least one anxiolytic drug.

Posttraumatic stress symptoms: From the total sample, $71,4 \%(n=10)$ of the participants scored 24 or higher in the Portuguese version of the PTSD checklist. ${ }^{21}$

Neuropsychiatric symptoms and caregiver disruption: A total of $30.8 \%(n=4)$ of patients had moderate neuropsychiatric symptoms as defined by a total NPI score between 20 and $50(\min =0, \max =36$, mean $=12.08$, $\mathrm{SD}=12.12$ ) in the NPI Portuguese version. ${ }^{34}$ Around $77 \%$ ( $n=10$ ) reported one or more domains of neuropsychiatric disturbance. The most common neuropsychiatric disturbances were the following: depression (54\%; $n=7)$, nighttime behavior disturbances ( $54 \% ; n=7)$, irritability/lability (46\%; $n=6)$, agitation/aggression (46\%; $n=6)$, apathy/ indifference $31 \%(n=4)$, and anxiety $31 \%(n=4)$. Caregiver disruption scores varied between 0 and 19 (mean $=6.62$, median = 5). In $38.5 \%(n=5)$ of the subjects, the total score of caregiver disruption was over 5 , which is considered clinically relevant.

Activities of daily living and return to work: From all the patients, $57 \%(n=8)$ lost at least one point in the Portuguese version of the IADL questionnaire. ${ }^{16}$ Also, $93 \%$ $(n=13)$ of patients were active when the SAH occurred. Ten years after the event, $42.8 \%(n=6)$ was not active anymore ( $7 \%$ unemployed and $36 \%$ with early retirement). Patients who returned to work after the event took on average 4.5 months to return $(\min =2, \max =12, \mathrm{SD}=3.35)$. In $35.7 \%$ of the cases $(n=5)$, this occurred because patients' working hours and / or responsibilities were reduced.

\section{DISCUSSION}

Surviving a potentially lethal neurological event can be a life-changing experience, not only due to the neurological sequelae but also due to the psychological reaction of the individual in its social context. Our study aimed to increase the understanding of the long-term outcomes of aSAH survivors, regarding high-level cognitive functioning, personality, and neuropsychiatric symptoms.

In a sample of young and professionally active individuals that survived an aSAH with a good neurological outcome, we identified a surprisingly high prevalence of neuropsychiatric symptoms and functional deficits ten years after the neurological event.

Analyzing the qualitative data, we found that in more than half of the cases, either the patient or the family informant reported significant and persistent personality changes after the event. Increased irritability, anxiety symptoms, and concentration deficits were consistently reported and pointed out as the cause of significant burdens to the patient and family. Importantly, none of the patients had been questioned before by a health professional about these symptoms and their implications. Our data are consistent with a recent follow-up study on good-outcome survivors of an aSAH, in which the authors reported that $31 \%$ of the patients believed that close relatives noticed changes in their psychological condition as a result of the event. ${ }^{35}$

One of our participants manifested clear hypomanic symptoms after the event, being overactive and overtalkative, showing reckless behavior, and having a consistently hyperthymic mood. There was no record of previous mood changes or any significant psychiatric family history. To our knowledge, there are no reported cases of persistent hypomanic or maniac features many years after an aSAH, although they have been reported during the acute phase. ${ }^{11}$ Obsessive, prolific artistic output arising after a subarachnoid hemorrhage has also been described previously. ${ }^{36}$

Another important detail is that all the participants manifested their satisfaction with being followed up, and it was reported to decrease their anxiety of recurrence. The patients also complained that they had not been given much information regarding their prognosis and the risk of recurrence and were satisfied to be given an opportunity to discuss this.

Focusing on the quantitative data, it is striking that all domains of HRQL were impaired, particularly vitality and mental health, thus reflecting impairment in high-level cognitive and emotional functioning, as opposed to physical deficits, which are traditionally given more importance.

The cognitive status of the patients was also surprising, especially for a sample of professionally active and educated patients. Verbal memory, learning, and visuospatial functions were the most significantly impaired domains, which could explain the significant cognitive complaints. This is concordant with the fact that, after the event, most patients needed to work fewer hours or even assume fewer responsibilities. It is impressive that none looked for medical attention regarding these symptoms, despite clearly assuming them to be sequelae of the aSAH. To what extent a cognitive rehabilitation program could have helped them to fully recover their previous level of functioning seems an important question to consider.

The prevalence of psychiatric symptoms such as anxiety and depression was also striking. According to the recent national epidemiological study of mental health conducted in Portugal, the lifetime prevalence figures of any anxiety disorder or any mood disorder are $25.8 \%$ and $19.3 \%$, respectively, for the adult population. ${ }^{37}$ In our sample, the figures are much higher, with $40 \%$ of the patients having significant anxiety features and around $35 \%$ scoring above the cut-off value for depression in the HADS.

The estimated rate of anxiolytics use was $23.4 \%$ for females and $9.8 \%$ for males in the aforementioned epidemiological study. ${ }^{37}$ We identified a prevalence of $30 \%$ in our sample of aSAH survivors.

Lifetime PTSD prevalence in the general Portuguese population is estimated to be around $5 \% .{ }^{37}$ In this sample, only less than $30 \%$ of the patients were free of significant PTSD symptoms, and importantly, none of them had been previously questioned about PTSD or asked for specialized help. 
The prevalence of neuropsychiatric symptoms was another relevant finding, with anxiety, agitation, and irritability being the most frequent complaints and generating significant family distress. This is in accordance with the results of a recent cross-sectional study that evaluated patients $1-4$ years after SHA. ${ }^{38}$ The authors reported that forty-two $(41 \%)$ patients had one or more domains of neuropsychiatric disturbance, frequently including agitation/ aggression, depression, apathy/indifference, irritability/lability, and appetite/eating disturbance.

Despite all participants being classified and having had a good neurological recovery, all the patients lost at least 1 point in the IADL regarding tasks such as ability to use a telephone, shopping, food preparation, handling finances; which is surprising in a sample of young, active, and relatively educated patients with many social responsibilities.

The reported results are concordant with another study performed in the same hospital about 10 years before, in which minor cognitive deficits and high scores on a depression scale were frequent findings in a cohort of perimesencephalic SAH patients. The length of follow-up of the participants in this study varied from 3 months to 7 years, but half of the patients $(n=9)$ were followed up for more than 4 years after the event. ${ }^{39}$

The present study has several limitations that should be mentioned. Firstly, our sample is small, and we could not establish a comparison with pre-event data. We were not able to investigate statistically significant differences between our sample and the general population, and it was not possible to control for important covariates such as education, age at the event, and severity of aSAH. A battery of more specific neuropsychological tests would have been important to refine the characterization of a patient's deficits. Finally, it was not possible to investigate anatomical and/or functional brain changes and establish correlations with clinical profiles. Neuroimaging studies suggested that the long-term cognitive deficits after aSAH can be attributed to macroscopic changes in brain structure (i.e., reduced mesiotemporal volumes, ischemic lesions, global brain atrophy)..$^{40}$ In the acute phase of a $\mathrm{SAH}$, higher hematic densities in the left and right basal sylvian fissures and in the 4th ventricle have been associated with denial, as was the occurrence of hydrocephalus. ${ }^{11}$ Apathy was associated with blood in the left or right lateral ventricles. ${ }^{11}$

Studies in animal models have also suggested a correlation with changes at the synaptic level. ${ }^{40}$ However, to our knowledge, correlations between neuroimaging findings and clinical profiles in the long term are still lacking detailed characterization.

Nonetheless, our results are still informative, reinforcing the growing body of evidence on this topic, strongly suggesting that we still lack proper and timely screening tests for uncovering important emotional and cognitive problems when following up survivors of aSAH.

\section{CONCLUSION}

In our sample, many years after an aSAH, and despite a successful treatment and good neurological recovery, patients reported significant sequelae in high-level functioning, with functional impairment in basic activities of daily living, decreased quality of life, and a high prevalence of psychiatric symptoms. This is especially relevant in a sample of young patients with many personal and social responsibilities.

Obtaining a better understanding of how surviving an aSAH impacts cognition and mental health in the long term could inform the development of more efficient follow-up programs. This would allow survivors to fully explore the potential to resume their previous level of functioning, thus improving their quality of life, and, in a broader perspective, decreasing the burden to society. In particular, paying attention to the psychological variables and neuropsychiatric symptoms and systematically including these in follow-up programs could have an enormous impact in terms of public health. In our opinion, the instruments used here were simple and quickly administered and thus could be embedded in routine clinical practice.

More studies are needed in order to define optimal follow-up strategies, regarding not only the content of the evaluations but also their timing.

\section{ACKNOWLEDGMENT}

We would like to thank all the participants who kindly agreed to participate in this study.

\section{PROTECTION OF HUMANS AND ANIMALS}

The authors declare that the procedures were followed according to the regulations established by the Clinical Research and Ethics Committee and to the Helsinki Declaration of the World Medical Association.

\section{DATA CONFIDENTIALITY}

The authors declare having followed the protocols in use at their working center regarding patients' data publication.

\section{CONFLICTS OF INTEREST}

All authors report no conflict of interest.

\section{FUNDING SOURCES}

This research received no specific grant from any funding agency in the public, commercial, or not-for-profit sectors.

\section{REFERENCES}

1. van Gijn J, Kerr RS, Rinkel GJ. Subarachnoid haemorrhage. Lancet. 2007;369:306-18.

2. de Rooij NK, Linn FH, van der Plas JA, Algra A, Rinkel GJ. Incidence of subarachnoid haemorrhage: a systematic review with emphasis on

region, age, gender and time trends. J Neurol Neurosurg Psychiatry. 2007;78:1365-72.

3. van Gijn J, Rinkel GJ. Subarachnoid haemorrhage: diagnosis, causes and management. Brain. 2001;124:249-78. 
4. Vilkki JS, Juvela S, Siironen J, Ilvonen T, Varis J, Porras M. Relationship of local infarctions to cognitive and psychosocial impairments after aneurysmal subarachnoid hemorrhage. Neurosurgery. 2004;55:790-802.

5. Hackett ML, Anderson CS. Health outcomes 1 year after subarachnoid hemorrhage: an international population-based study. The Australian Cooperative Research on Subarachnoid Hemorrhage Study Group. Neurology. 2000;55:658-62.

6. Carter BS, Buckley D, Ferraro R, Rordorf G, Ogilvy CS. Factors associated with reintegration to normal living after subarachnoid hemorrhage. Neurosurgery. 2000;46:1326-33.

7. Wermer MJ, Kool H, Albrecht KW, Rinkel GJ, Aneurysm Screening after Treatment for Ruptured Aneurysms Study Group. Subarachnoid hemorrhage treated with clipping: long-term effects on employment, relationships, personality, and mood. Neurosurgery. 2007;60:91-7.

8. Tomberg T, Orasson A, Linnamägi Û, Toomela A, Pulver A, Asser T. Coping strategies in patients following subarachnoid haemorrhage. Acta Neurol Scand. 2001;104:148-55.

9. Hop JW, Rinkel GJ, Algra A, van Gijn J. Changes in functional outcome and quality of life in patients and caregivers after aneurysmal subarachnoid hemorrhage. J Neurosurg. 2001;95:957-63.

10. Buchanan KM, Elias LJ, Goplen GB. Differing perspectives on outcome after subarachnoid hemorrhage: the patient, the relative, the neurosurgeon. Neurosurgery. 2000;46:831-8.

11. Caeiro L, Santos CO, Ferro JM, Figueira ML. Neuropsychiatric disturbances in acute subarachnoid haemorrhage. Eur $\mathrm{J}$ Neurol. 2011;18:857-64.

12. Preiss M, Koblihova J, Netuka D, Bernardova L, Charvat F, Benes V. Verbal memory capacity after treatment for ruptured intracranial aneurysm-the outcomes of three psychological tests: within a month, 1 year after and 5-7 years after treatment. Acta Neurochir. 2012;154:417-22.

13. Noble AJ, Schenk T. Which variables help explain the poor healthrelated quality of life after subarachnoid hemorrhage? A meta-analysis. Neurosurgery. 2010;66:772-83.

14. Ginó S, Guerreiro M, Garcia C, Mendonça A, Guerreiro M. Subjective memory complaints (QSM). Escalas e testes na demência $2^{a}$ ed. Lisboa: Grupo de Estudos de Envelhecimento Cerebral e Demência; 2008. p. 117-20

15. Freitas S, Simoes MR, Alves L, Santana I. Montreal Cognitive Assessment (MoCA): normative study for the Portuguese population J Clin Exp Neuropsychol. 2011;33:989-96.

16. Araújo F, Pais Ribeiro J, OliveiraA, Pinto C, Martins T. Validação da Escala de Lawton e Brody numa amostra de idosos não institucionalizados. Livro de Atas do $7^{\circ}$ Congresso Nacional de Psicologia da Saúde. Porto: Sociedade Portuguesa de Psicologia da Saúde; 2008. p. 217-20.

17. Ferreira PL. Criação da versão portuguesa do MOS SF-36. Parte I Adaptação cultural e linguística. Acta Med Port. 2000;13:55-66.

18. Ferreira PL. Criação da versão portuguesa do MOS SF-36. Parte II Teste de validação. Acta Med Port. 2000;13:119-27.

19. Pais-Ribeiro J, Silva I, Ferreira T, Martins A, Meneses R, Baltar M Validation study of a Portuguese version of the Hospital Anxiety and Depression Scale. Psychol Health Med. 2007;12:225-35.

20. Ferreira $A$, Ribeiro $O$, Martins $S$, Fernandes L. Inventário neuropsiquiátrico (NPI): contributo para a validação da versão portuguesa. Sinapse. 2014;14:152.

21. Marcelino D, Gonçalves SP. Perturbação pós-stress traumático: características psicométricas da versão portuguesa da Posttraumatic Stress Disorder Checklist - Civilian Version (PCL-C). Rev Port Saúde Pública. 2012;30:71-5.
22. von Elm E, Altman DG, Egger M, Pocock SJ, Gotzsche PC, Vandenbroucke JP, et al. The Strengthening the Reporting of Observational Studies in Epidemiology (STROBE) statement: guidelines for reporting observational studies. J Clin Epidemiol. 2008;61:344-9.

23. Nasreddine ZS, Phillips NA, Bedirian V, Charbonneau S, Whitehead V, Collin I, et al. The Montreal Cognitive Assessment, MoCA: a brief screening tool for mild cognitive impairment. J Am Geriatr Soc. 2005;53:695-9.

24. Schweizer TA, Al-Khindi T, Macdonald RL. Mini-Mental State Examination versus Montreal Cognitive Assessment: rapid assessment tools for cognitive and functional outcome after aneurysmal subarachnoid hemorrhage. J Neurol Sci. 2012;316:137-40.

25. Wong GK, Lam SW, Wong A, Lai M, Siu D, Poon WS, et al. MoCAassessed cognitive function and excellent outcome after aneurysmal subarachnoid hemorrhage at 1 year. Eur J Neurol. 2014;21:725-30.

26. Schmand B, Jonker C, Hooijer C, Lindeboom J. Subjective memory complaints may announce dementia. Neurology. 1996;46:121-5.

27. Lawton MP, Brody EM. Assessment of older people: self-maintaining and instrumental activities of daily living. Gerontologist. 1969;9:179-86.

28. Ware JE Jr, Gandek B. Overview of the SF-36 Health Survey and the International Quality of Life Assessment (IQOLA) Project. J Clin Epidemiol. 1998;51:903-12.

29. Bjelland I, Dahl AA, Haug TT, Neckelmann D. The validity of the Hospital Anxiety and Depression Scale. an updated literature review. J Psychosom Res. 2002:52:69-77.

30. Cummings JL, Mega M, Gray K, Rosenberg-Thompson S, Carusi DA, Gornbein J. The Neuropsychiatric Inventory: comprehensive assessment of psychopathology in dementia. Neurology. 1994;44:2308-14.

31. Blanchard EB, Jones-Alexander J, Buckley TC, Forneris CA Psychometric properties of the PTSD Checklist (PCL). Behav Res Ther. 1996;34:669-73

32. Ferreira PL, Santana P. Percepção de estado de saúde e de qualidade de vida da população activa: contributo para a definição de normas portuguesas. Rev Port Saúde Pública. 2003;21:15-30.

33. Alagoa Joao A, Maroco J, Gino S, Mendes T, de Mendonca A, Martins IP. Education modifies the type of subjective memory complaints in older people. Int J Geriatr Psychiatry. 2016;31:153-60.

34. Ferreira AR, Martins S, Ribeiro O, Fernandes L. Validity and reliability of the European portuguese version of neuropsychiatric inventory in an institutionalized sample. J Clin Med Res. 2015;7:21-8.

35. Preiss M, Netuka D, Koblihova J, Bernardova L, Charvat $F$ Kratochvilova D, et al. Quality of life 1 year after aneurysmal subarachnoid hemorrhage in good outcome patients treated by clipping or coiling. J Neurol Surg A Cent Eur Neurosurg. 2012;73:217-23.

36. Lythgoe MF, Pollak TA, Kalmus M, de Haan M, Chong WK. Obsessive, prolific artistic output following subarachnoid hemorrhage. Neurology. 2005;64:397-8.

37. Caldas de Almeida J, Xavier M. Estudo epidemiológico nacional de saúde mental. Lisboa: Faculdade de Ciências Médicas da Universidade Nova de Lisboa; 2013

38. Wong GK, Lam SW, Chan SS, Lai M, Tse PP, Mok V, et al. Neuropsychiatric disturbance after aneurysmal subarachnoid hemorrhage. J Clin Neurosci. 2014;21:1695-8.

39. Madureira S, Canhao P, Guerreiro M, Ferro JM. Cognitive and emotional consequences of perimesencephalic subarachnoid hemorrhage. J Neurol. 2000;247:862-7.

40. Al-Khindi T, Macdonald RL, Schweizer TA. Cognitive and functional outcome after aneurysmal subarachnoid hemorrhage. Stroke. 2010;41:e519-36. 